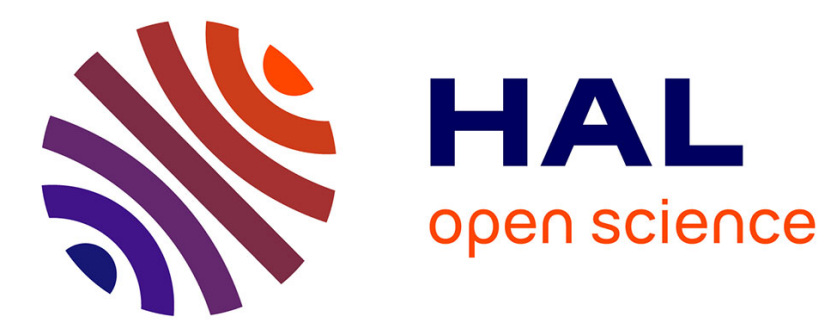

\title{
Laparoscopic distal pancreatectomy: Surgical technique
}

\author{
S. Dokmak, B. Aussilhou, F.S. Ftériche, O. Soubrane, A. Sauvanet
}

\section{To cite this version:}

S. Dokmak, B. Aussilhou, F.S. Ftériche, O. Soubrane, A. Sauvanet. Laparoscopic distal pancreatectomy: Surgical technique. Journal of Visceral Surgery, 2019, 156, pp.139 - 145. 10.1016/j.jviscsurg.2018.12.006 . hal-03486553

\section{HAL Id: hal-03486553 \\ https://hal.science/hal-03486553}

Submitted on 20 Dec 2021

HAL is a multi-disciplinary open access archive for the deposit and dissemination of scientific research documents, whether they are published or not. The documents may come from teaching and research institutions in France or abroad, or from public or private research centers.
L'archive ouverte pluridisciplinaire HAL, est destinée au dépôt et à la diffusion de documents scientifiques de niveau recherche, publiés ou non, émanant des établissements d'enseignement et de recherche français ou étrangers, des laboratoires publics ou privés.

\section{다)(1) $(5$}

Distributed under a Creative Commons Attribution - NonCommerciall 4.0 International 


\section{Laparoscopic distal pancreatectomy: Surgical technique}

Safi Dokmak MD (1), Béatrice Aussilhou MD(1), Fadhel Samir Ftériche MD(1), Olivier Soubrane MD (1), Alain Sauvanet MD (1).

(1): Department of Hepatic-biiary-pancreatic Surgery and Liver Transplantation, Beaujon Hospital, 100 Bd du Général Leclerc, 92110 Clichy (France) - [Assistance Publique Hôpitaux de Paris] University Paris 7 Denis Diderot.

Corresponding author: Safi Dokmak, M.D

E-mail address: safi.dokmak@bjn.aphp.fr

Telephone: +33140875797

Fax: +33140840926

The authors have no conflict of interest in relation to this study.

\section{Introduction}

The laparoscopic approach is technically well-suited for left pancreatectomy since the dissection is performed away from the vascular axes, a reconstruction phase is not necessary, and the pancreas and blood vessels can be controlled with mechanical stapling and/or thermo-fusion forceps without any need for ligatures. Laparoscopic left pancreatectomy is likely to see a major increase in use because it can be performed early in the surgeon's experience and, thanks to increased fortuitous discovery by imaging studies, 
pancreatic lesions with low malignant potential are being diagnosed more and more frequently. In a recent randomized study that compared the minimally invasive approach $(n=51)$ to the classical open laparotomy approach $(n=57)$, the risk of pancreatic fistula in the laparoscopic group was not found to be statistically significantly decreased (39\% vs. $23 \%, p=0.07)$ but there was an advantage for the median length of stay ( 6 vs. 8 days, $p<0.001$ ) (1). Relative contraindications for laparoscopy are:

1) vascular or adjacent organ invasion,

2) acute or chronic pancreatitis,

3) bulky lesions with signs of segmental portal hypertension, and

4) the need for an extended pancreatectomy when parenchymalsparing pancreatectomy proves unfeasible, since this is more difficult by the laparoscopic approach.

Although it is generally recommended that the splenic vessels be divided before transecting the pancreas or that the splenic artery be divided before the splenic vein, in our experience, we always recommend initial transection of the pancreas, followed by a division of the vein, and finally of the splenic artery. This approach is easier, faster and more secure in difficult situations such as obesity and/or in case of inflammatory adhesions or tumors. We believe that the principles of conventional surgery cannot always be applied in laparoscopic surgery. According to the positioning of the optics and trocars, the surgeon's vision is caudo-cranial rather than anteroposterior as with conventional open surgery. The structures located towards the lower edge of the pancreas are more easily visible, accessible and easy to control. For example, after transection of the pancreatic isthmus, the splenic vein is easily accessible and visible in the operative field relative to the splenic artery which is situated in a higher and posterior plane and which is most often hidden by the overlying pancreatic parenchyma and peripancreatic fat, making its control more difficult. 
Herein, we describe our technique of laparoscopic left splenopancreatectomy

\section{Figure 1: Installation}

The patient is positioned supine with the legs apart, the right arm alongside the body and the left arm extended at an angle less than $90^{\circ}$ to the trunk, Two $10-12-\mathrm{mm}$ trocars and three 5-mm trocars are introduced after the initial optical trocar is inserted by the open technique. The operator stands to the patient's right, the assistant between the legs and the nurse to the right of the operator. If the exposure or operative view is not optimal, the optic trocar can be shifted to the left hypochondrium and the operative trocar to the umbilical site. In all cases we avoid the crossing of arms between the operator and the assistant.

\section{Figure 2: Division of the gastro-colic ligament}

The gastro-colic ligament is widely opened preserving the gastroepiploic arcade serving the greater curvature of the stomach; the colo-epiploic detachment is to be avoided because it takes longer to perform while the risk of a colonic wound is not zero. We recommend that the short gastric vessels not be divided until after the splenic vessels have been controlled because the occurrence of hemorrhage at this stage will be difficult to control.

\section{Figure 3: Gastric hanging maneuver}

Optimal gastric retraction is necessary in order to obtain good exposure of the pancreatic gland (2). A dissector is passed behind the stomach and through the lesser omentum to the right of the left gastric pedicle aiming towards the lower surface of the left hepatic lobe (Fig. 3a). A tape is introduced through an epigastric trocar placed to the left of the xiphoid process to encircle the stomach. The stomach is then rotated about its horizontal axis so that the posterior aspect becomes anterior, in order to move the epiplöon away from the operating field. The tape is positioned in the center of the 
stomach but can be moved to the right or left to facilitate exposure of the isthmus, body or tail of the pancreas (Fig. 3b). The epigastric trocar is then completely removed. This provides excellent exposure of the pancreatic gland and allows one to more easily complete the release of adhesions on the anterior aspect of the pancreas and the division of the gastro-epiploic ligament on the right and on the left (Fig 3c).

\section{Figure 4: Control and transection of the pancreas}

The dissection begins with the release of the inferior border of the pancreas in order to find the correct dissection plane, to be able to work around the pancreatic gland without tearing it, and to create a space into which a compressive sponge can easily be inserted in case of hemorrhage. This dissection allows identification of the mesenterico-portal venous axis and the entry point of the splenic vein.

We then dissect fatty tissue and lymph nodes at the origin of the hepatic artery and left gastric pedicle thus allowing identification of the hepatic artery along the upper edge of the pancreas. The retroisthmic passage is made using a dissector allowing a heavy suture to be passed behind the isthmus. The pancreas is transected with a mechanical stapler (Echelon $60^{\circledR}$, with 2.5 or $3.6 \mathrm{~mm}$, staples, Ethicon $^{\circledR}$ ) (Fig. 4a). If the retro-isthmic passage is difficult due to inflammation or vascular invasion, or if it is located near the gastroduodenal artery, we recommend a progressive and more precise transection of the pancreas in order to better identify the vascular structures and to avoid inadvertent stapling of the gastroduodenal artery. Before transecting the pancreas, it is necessary to check the pulsation in the hepatic artery. The artery that lies just above the isthmus is the hepatic artery and not the splenic artery! Once the pancreatic isthmus is transected, the splenic vein termination is evident and easily accessible in the operative field, in contrast to the origin of the splenic artery, which is generally not yet visible (Fig. 4b). 


\section{Figure 5: Division of the splenic vein}

The splenic vein can be either stapled or ligated. Thereafter, the nodal dissection proceeds along the left edge of the superior mesenteric artery with control of the small vascular and lymphatic collaterals and division of the perivascular nerve sheath to enable identification of the splenic artery at its lower edge. This dissection makes it possible to better identify, lengthen and increase the mobility of the origin of the splenic artery, thus facilitating its control. Ligation of the splenic vein first, will not increase the risk of splenic congestion as long as the splenic artery is rapidly controlled thereafter.

\section{Figure 6: Division of the splenic artery}

There is no risk of occluding the hepatic artery with the stapler if the end of the forceps was passed to the left of the left gastric pedicle (Fig. 6a). The splenic artery can be either stapled or ligated (Fig. 6b). Of course the splenic artery can be controlled before the splenic vein if it is easily accessible but, in our experience, this situation is far from being the most common.

\section{Figure 7: Mobilization of the specimen}

Mobilization is from right to left after lowering the splenic flexure and releasing the lower pole of the spleen. Along the superior border, we complete the division of the short gastric vessels and posterior gastric pedicles. If, at this stage, the exposure is not optimal, the suspension of the stomach must be relaxed and repositioned to retract the stomach medially and facilitate this action. Then the antero-superior gastric suspension is put back in place. The final stage is the division of the posterior attachments of the spleen and the removal of the specimen. This mobilization of the specimen can be difficult, especially in obese patients and may require in some cases, a handassisted approach.

Figure 8: Extraction of the specimen and drainage 
The procedure ends with verification of hemostasis, especially at the level of the transected pancreatic edge and along the greater curvature after the stomach suspension is released. The pancreatic staple line is drained by a small suction drain. The specimen is removed in a bag through a small suprapubic incision or through another previous abdominal scar.

\section{References}

1. de Rooij T, van Hilst J, van Santvoort H, Boerma D, van den Boezem P, Daams F, et al. Minimally Invasive Versus Open Distal Pancreatectomy (LEOPARD): A Multicenter Patientblinded Randomized Controlled Trial. Ann Surg. 2018 Aug 3. doi: 10.1097/SLA.0000000000002979. [E-pub ahead of print]

2. Dokmak S, Aussilhou B, Ftériche FS, et al. Hanging Maneuver for Stomach Traction in Laparoscopic Distal Pancreatic Resections: An Original Technique Applied in 218 Patients. Dig Surg 2017; 34: 89-94 


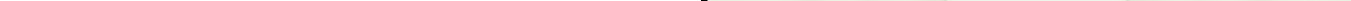




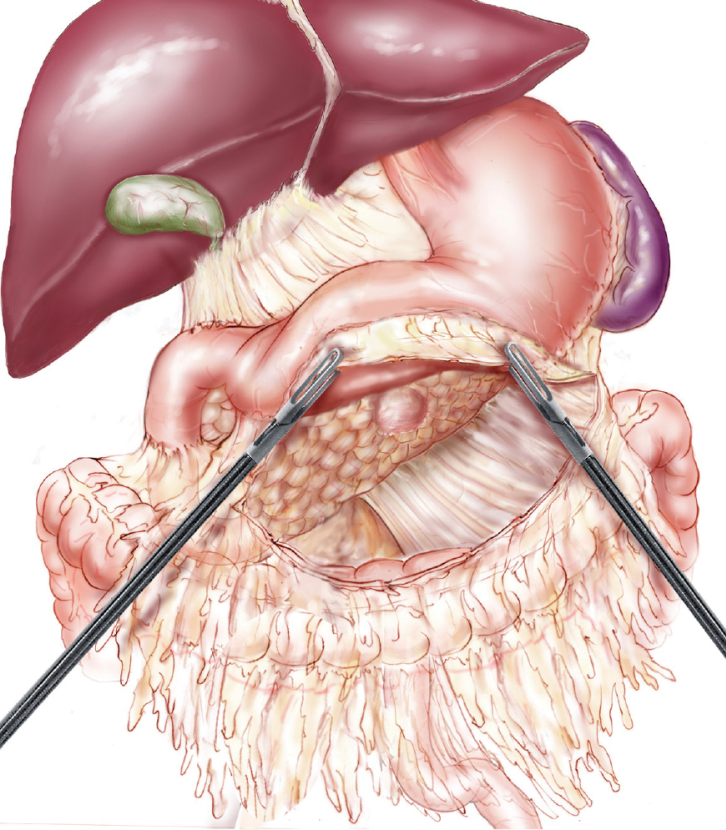




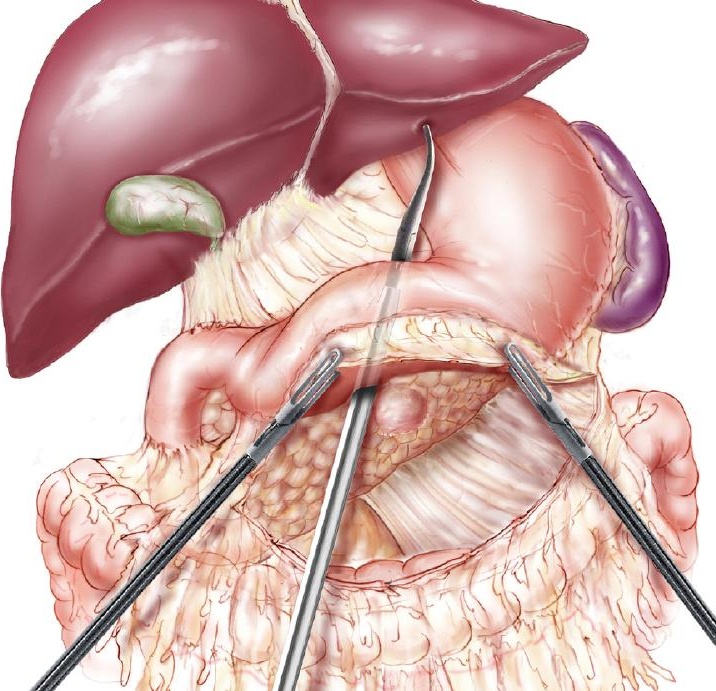




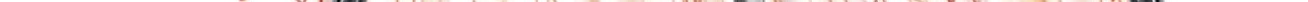




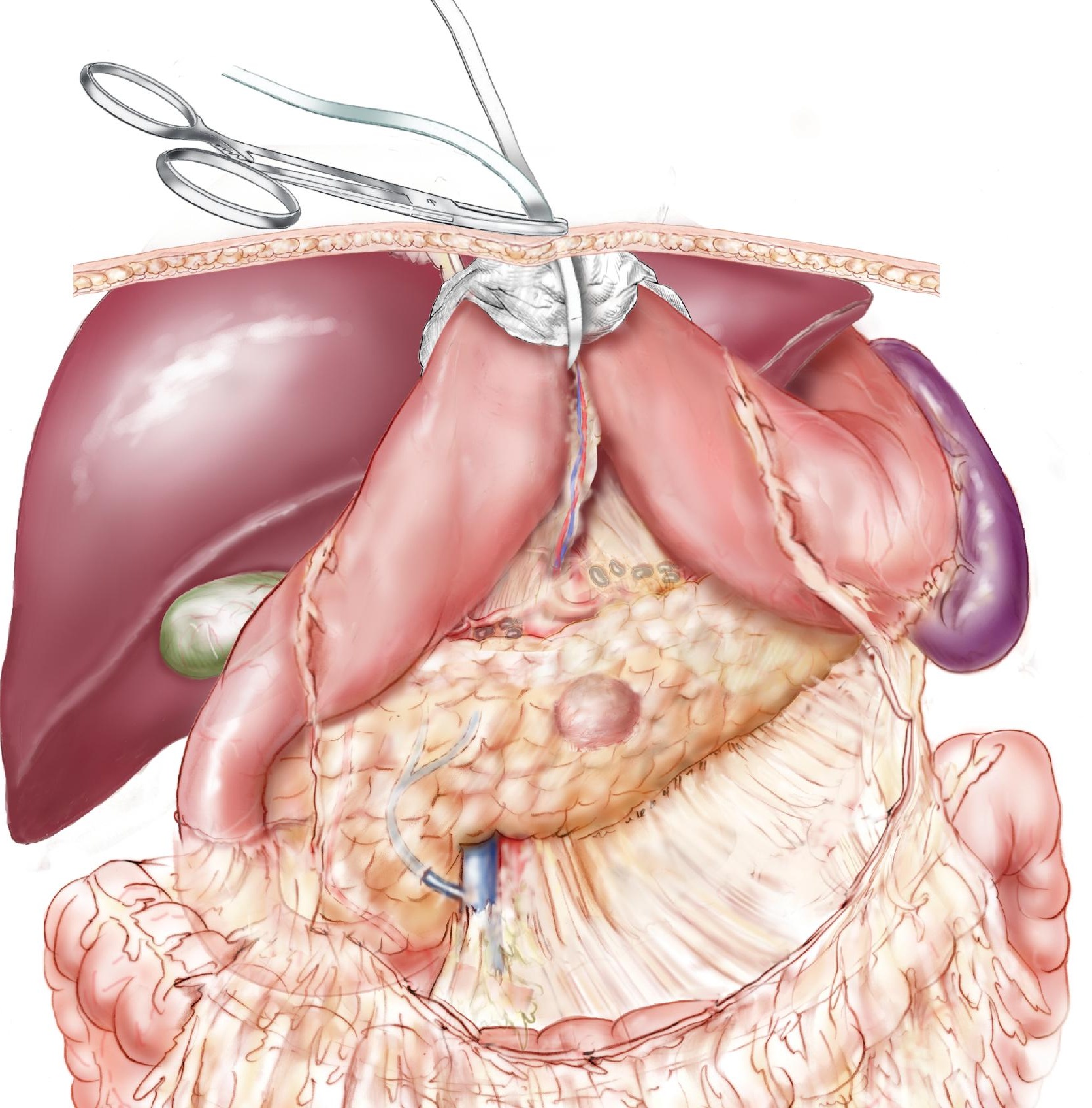




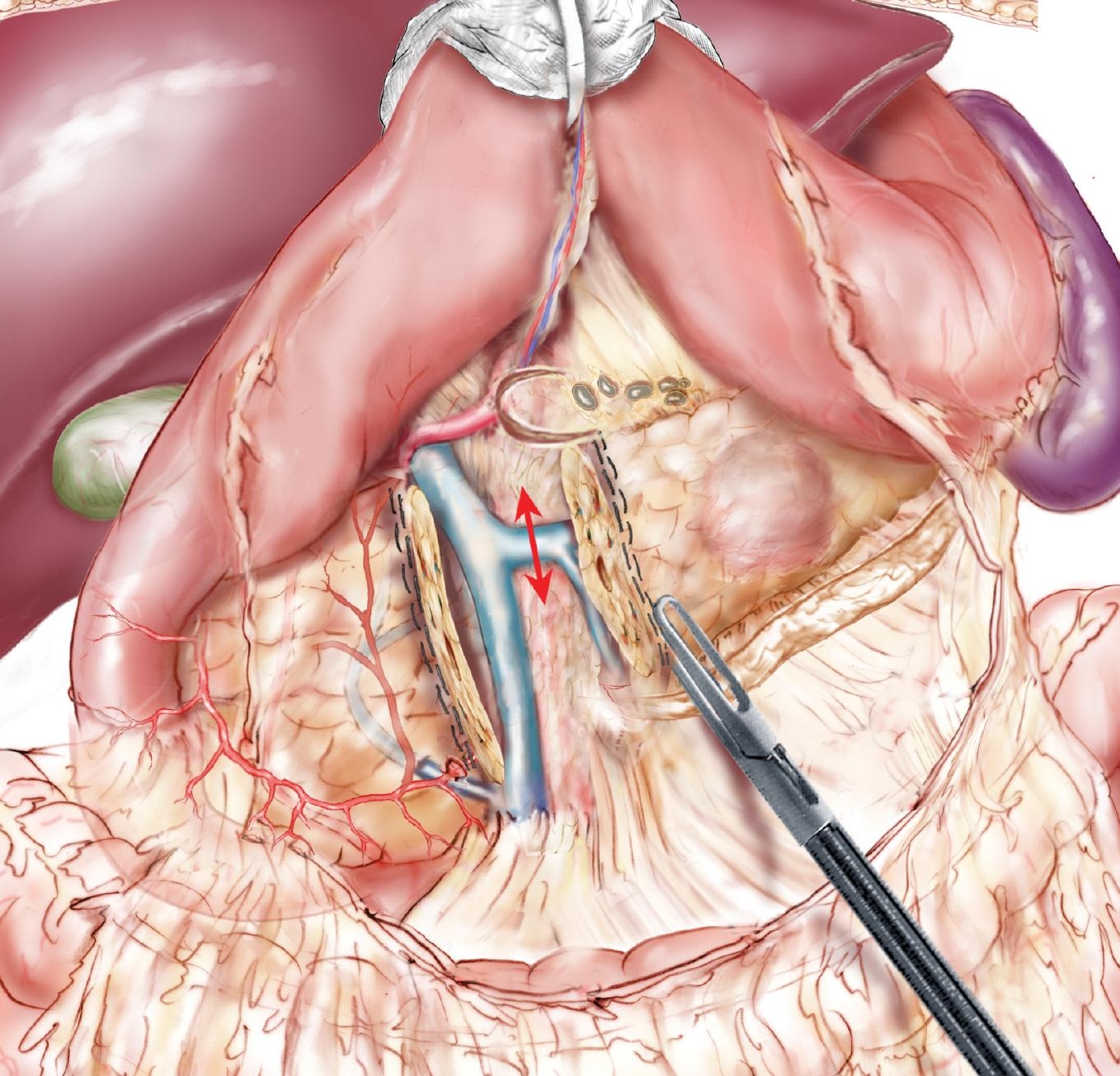




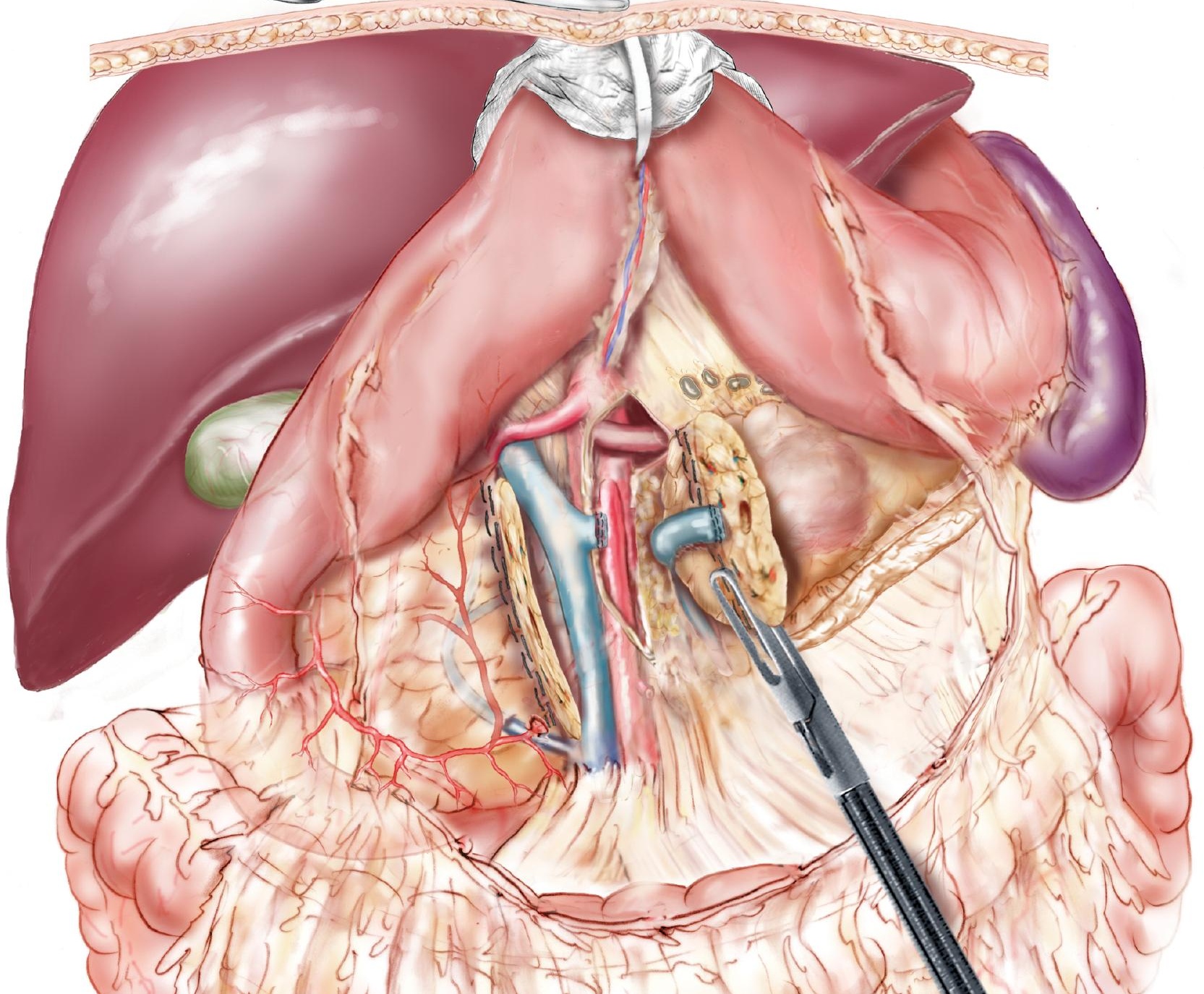



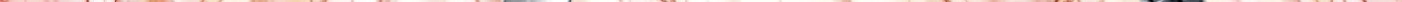


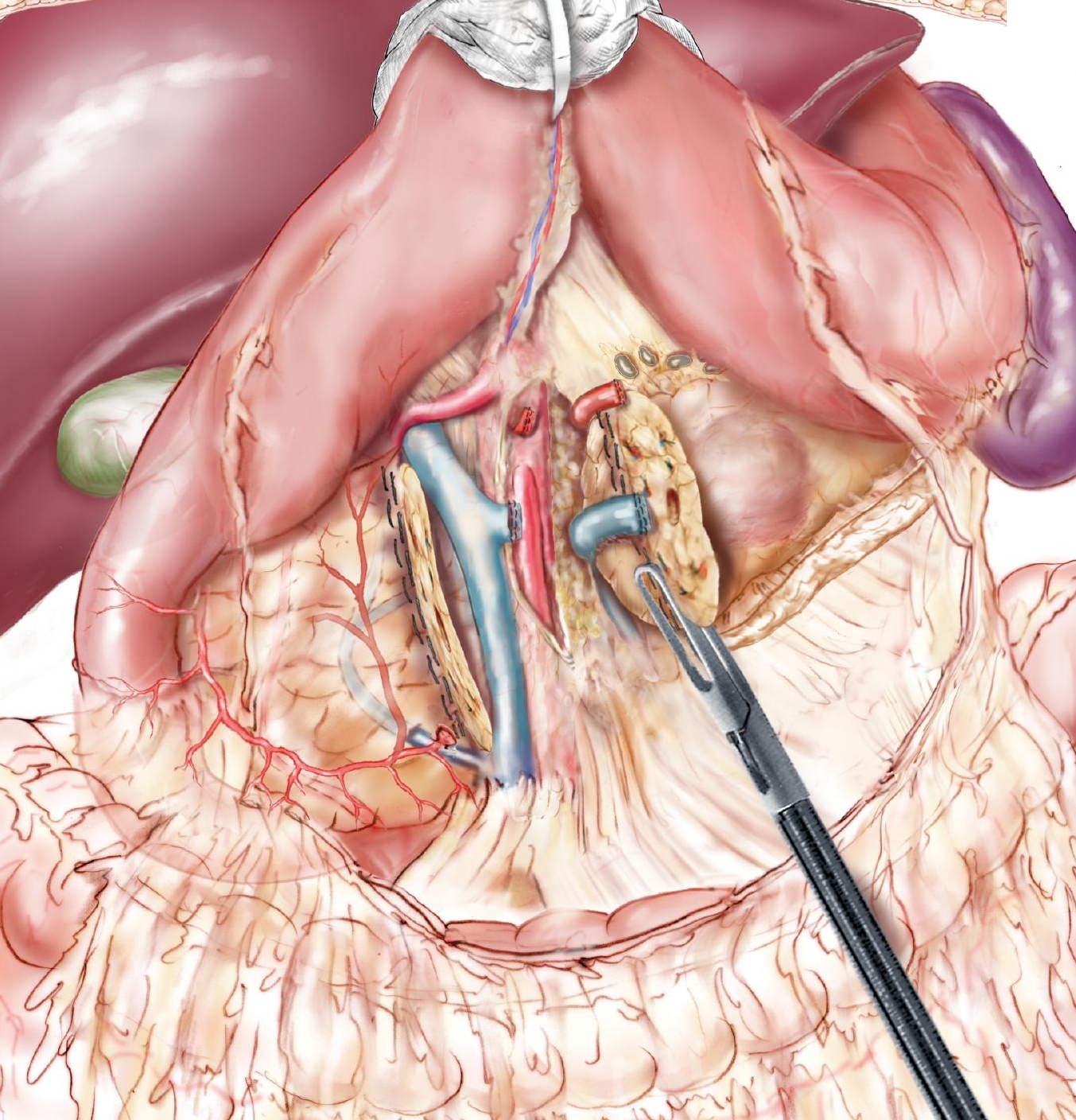



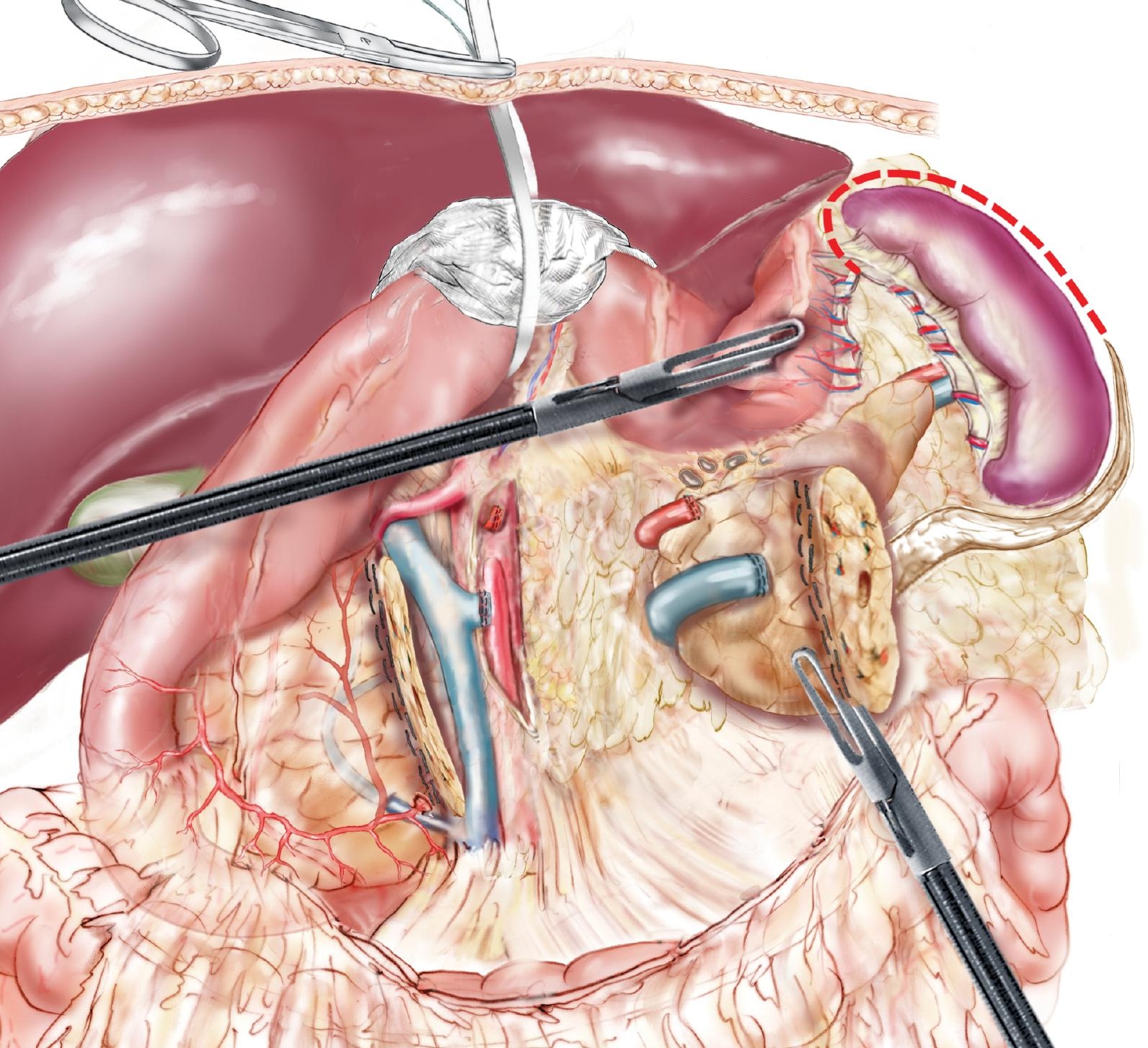


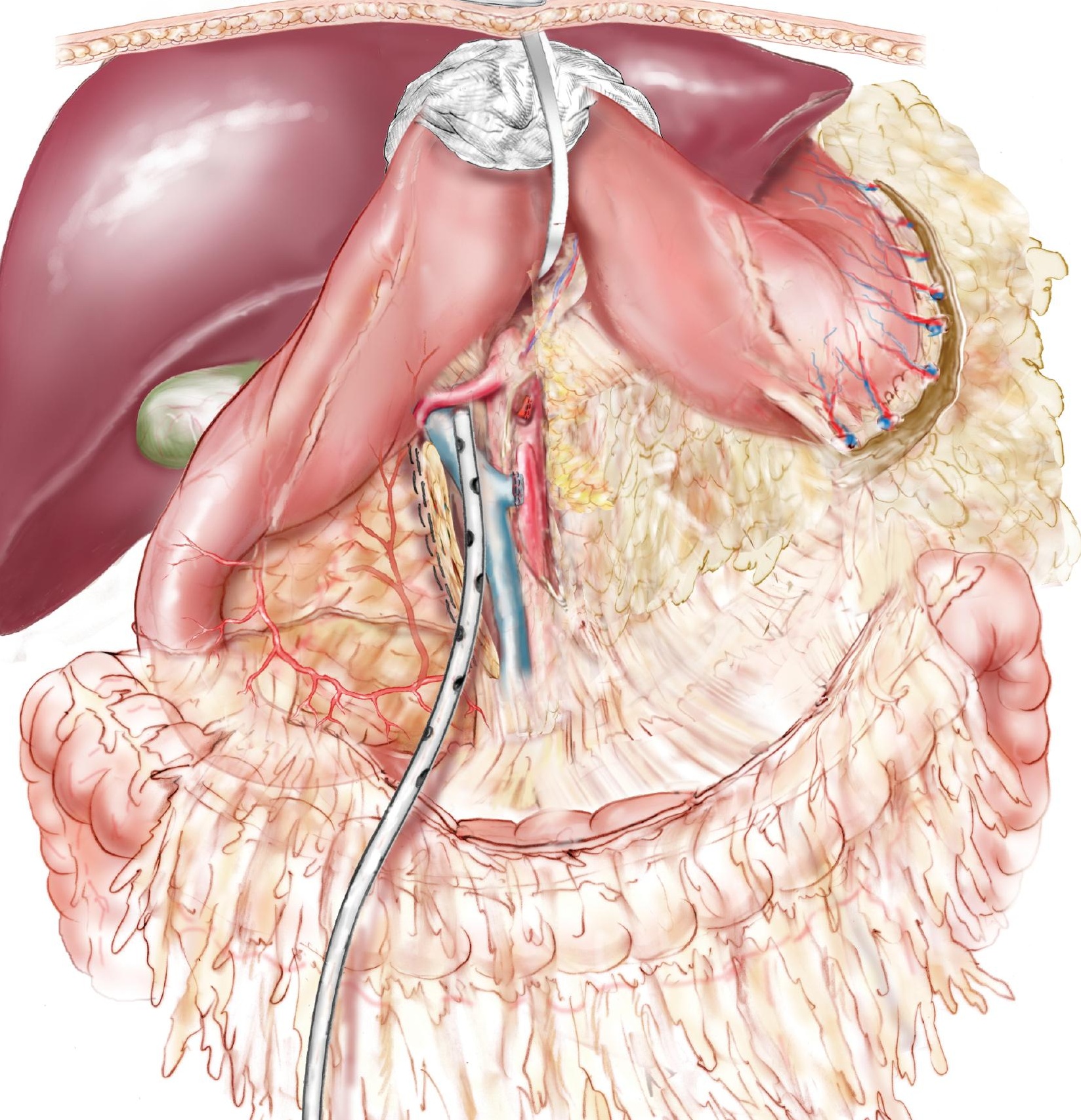

